\title{
Infrared Spectra of Chromatographically Fractionated Asphalts ${ }^{1}$
}

\author{
James E. Stewart
}

\begin{abstract}
Undegraded and weathered specimens of three roofing asphalts were chromatographically separated into three components after removal of the asphaltenes. The infrared absorption spectra of the fractions, recorded in the 2- to 15- $\mu$ spectral region, provide information about the chemical constitution of the material, the differences among asphalts from different sources, and the changes in constitution produced by weathering.
\end{abstract}

\section{Introduction}

Work on the constitution of asphalt and the degradation of asphalt on weathering has been under way at the National Bureau of Standards for some time. This work has been facilitated greatly by the development of chromatographic techniques [1] ${ }^{2}$ that permit the separation of structurally similar components for chemical and physical study. One phase of this study involved the use of infrared spectroscopy in an attempt to elucidate the chemical structure of the asphalt components and to determine changes that occur in the components when the asphalts are weathered. Infrared spectroscopy $[2,3]$ has been useful in studying the chemical structure of chromatographically fractionated petroleums of the type used as extender oils in synthetic rubber. It seemed reasonable, therefore, to apply infrared methods to the study of asphalts as well.

The purpose of this report is to present the results of a brief study of three airblown roofing asphalts of different origin. These asphalts are product 3 of asphalts I, II, and III, the properties of which were reported in detail by Greenfeld [4]. The asphalts and their components will be referred to as I, II, and III, respectively, in the following discussion. Both undegraded materials and specimens degraded by 30 months of natural weathering were examined.

\section{Experimental Procedures}

The asphalts were separated into four groups of components by L. R. Kleinschmidt of the NBS Floor, Roof, and Wall Covering Section. Normal pentane was used for the primary separation of the asphalts into asphaltenes and maltenes. The maltenes were fractionated further [1] into three groups of components, designated as water-white oils, dark oils, and asphaltic resins, by eluting the $n$-pentane soluble portions of the asphalts from a fuller's-earth column, with $n$-pentane, methylene chloride, and methyl ethyl ketone.

The distribution of components in the three asphalts, both before and after 30 months of exposure outdoors at the National Bureau of Standards, is

1 This work was supported jointly by the Asphalt Roofing Industry Bureau and the National Bureau of Standards.

2 Figures in brackets indicate the literature references at the end of this paper. given in table 1 . The distribution of components changes during weathering through the conversion of certain materials into water-soluble and volatile degradation products and by the alteration of adsorption properties because of chemical reactions.

Infrared absorption spectra were obtained with a Perkin-Elmer model 21 spectrophotometer, equipped with a sodium chloride prism. In order to avoid the interference of solvents it was decided to observe the material as liquid films. A cell was constructed that could be heated to about $60^{\circ} \mathrm{C}$ with a nichrome heater to facilitate loading the viscous asphaltic-resin fraction. Close control of temperature was not required because of the insensitivity of the absorption by these materials to temperature changes. The windows were separated by a lead spacer $0.05 \mathrm{~mm}$ thick, cut away at the top and bottom. A slot was cut in the top of one window. Samples were introduced into the slot and permitted to run into the cell, sometimes with the aid of suction applied at the bottom of the cell. After a spectrum was recorded, the sample was removed by suction and the cell rinsed with solvent. To assure constancy of the cell thickness, it was not disassembled during the series of measurements.

In addition, the spectra of the asphaltenes were obtained by suspending the material in potassium iodide pellets and in mineral oil. The use of

TABLE 1. Analyses of asphalts

\begin{tabular}{|c|c|c|c|}
\hline Type ... & I & II & III \\
\hline \multicolumn{4}{|c|}{ Unweathered material, stored 30 months in covered container } \\
\hline $\begin{array}{l}\text { Asphaltenes } \\
\text { Water-white oils } \\
\text { Dark oils } \\
\text { Asphaltic resins }\end{array}$ & $\begin{array}{r}\% \\
41.2 \\
27.7 \\
17.5 \\
8.8\end{array}$ & $\begin{array}{c}\% \\
41.0 \\
25.5 \\
20.5 \\
10.3\end{array}$ & $\begin{array}{r}\% \\
39.2 \\
23.6 \\
21.8 \\
10.8\end{array}$ \\
\hline \multicolumn{4}{|c|}{ Weathered, 30 months a } \\
\hline $\begin{array}{l}\text { Asphaltenes. } \\
\text { Water-white oils } \\
\text { Dark oils } \\
\text { Asphaltic resins }\end{array}$ & $\begin{array}{r}41.6 \\
18.7 \\
8.5 \\
9.0\end{array}$ & $\begin{array}{r}42.0 \\
20.1 \\
14.6 \\
9.4\end{array}$ & $\begin{array}{r}43.6 \\
19.1 \\
14.6 \\
8.5\end{array}$ \\
\hline Weight loss & 19.7 & 11.7 & 11.5 \\
\hline
\end{tabular}

a Percentage distribution of components based on the weights of the original coatings, which were 0.02 in. in thickness and 12 in. $^{2}$ in area. 
potassium iodide provided spectra that were free from losses by scatter, in contrast with those obtained by using potassium bromide. However, because of adsorbed water, alkali halide pellets absorb in the $3 \mu$ region where $\mathrm{O}-\mathrm{H}$ groups are observed. The use of mineral-oil suspensions permits observations in this important region.

\section{Infrared Spectra}

The value of infrared spectroscopy in studies like the present one arises from the fact that certain functional groups absorb infrared radiation in fairly narrow regions of wavelength, relatively independent of other functional groups in the molecule. Hence, in a mixture of many different compounds, common structural groups can often be determined. For example, all of the asphalt fractions absorb near $3.40,3.49,6.82$, and $7.2 \mu$ because of the stretching and angle-deformation vibrations of the $\mathrm{CH}_{2}$ and $\mathrm{CH}_{3}$ groups of alkanes. On the other hand, many functional groups have no characteristic absorption or absorb so weakly that they cannot be detected. $\mathrm{C}-\mathrm{S}$ and $\mathrm{S}-\mathrm{S}$ groups are of this nature. Furthermore, chemically different functional groups ofter have similar vibations and therefore absorb at a common wavelength. Conjugated carbon chains and aromatic rings, for example, have bands at $6.25 \mu$. In the analysis of the fractions that follows, liberal use has been made of the standard reference books in chemical infrared analysis; in particular, the book of Bellamy [5] has been invaluable.

\subsection{Water-White Oils}

The water-white oil fractions (fig. 1) are seen to be predominantly saturated aliphatics, with a slight aromatic content producing a ring vibration at $6.25 \mu$. Very likely the aromatic content is largely of a paradisubstituted nature leading to the absorption band at $12.2 \mu$. From the relative intensities of the 6.25 - and $12.2-\mu$ aromatic bands from sample to sample, it appears that samples II and III have about the same aromatic content, whereas sample I is more aromatic by a factor of about 2 or 3 . An idea of the mean chain length, and thus of branching, is obtained by observation of the intensities of the $\mathrm{C}-\mathrm{H}$ band at $13.8 \mu$ and the shoulder found on the short wavelength side of this band. In general, the longer chains absorb at longer wavelengths than the shorter chains. Simple III shows evidence of slightly more branching than sample II, and sample I is considerably more branched. This observation is verified by the intensities of the $\mathrm{CH}_{3}$ bands at $7.24 \mu$, the more highly branched samples showing stronger $\mathrm{CH}_{3}$ absorption.

The presence of cycloparaffins in hydrocarbon mixtures is believed [2] to result in increased absorption in the rather broad region centered at about $10.2 \mu$. Hence, sample III is slightly more cycloparaffinic in nature than II, and sample I is much more cycloparaffinic.

The water-white oil separated from a weathered sample II is almost identical to the unweathered sample, except for a slight decrease in intensity of
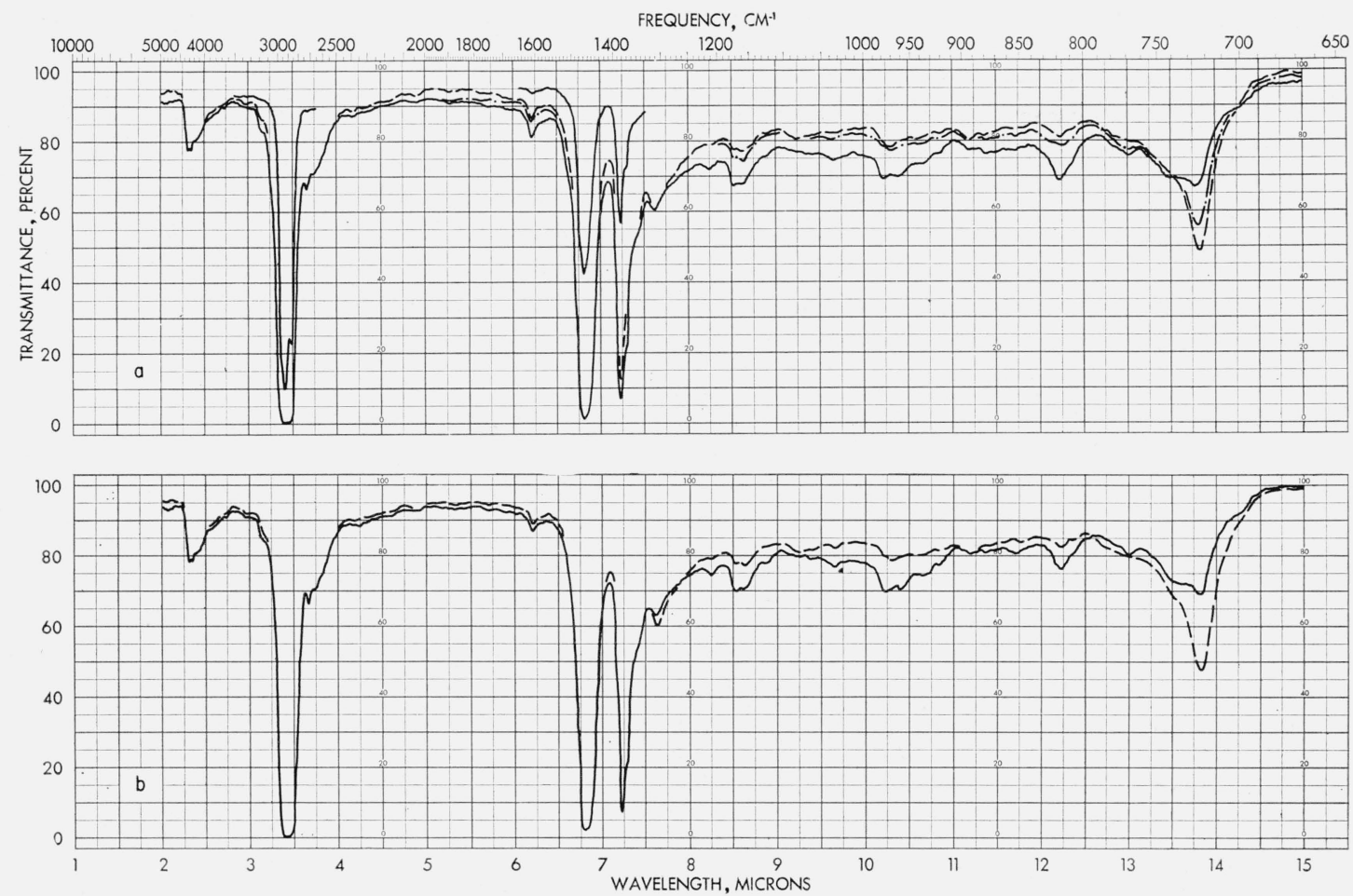

Figure 1. Infrared spectra of water-white oil fractions of asphalts.

$\mathrm{a}$, Unweathered; $\mathrm{b}$, weathered.

I, ; II, ; III, 
the aromatic bands and perhaps a slight reduction in branching. Sample III displays, in addition to reduced aromaticity, a more pronounced reduction in branching as well as reduced absorption in the cycloparaffin region. After weathering, the waterwhite oils from asphalts III and II are nearly identical, with the former being very slightly less branched. The aromatic and cycloparaffin absorption of sample I is reduced after weathering, but the branching seems to be unaltered.

The relatively greater loss of cycloparaffin and branched aliphatic components during weathering is in agreement with the greater reactivity of such compounds. Furthermore, sample I, which is richest in these compounds, loses a greater fraction of the water-white oils originally present (see table 1).

\subsection{Dark Oils}

The dark oils (fig. 2) are highly aromatic in nature, as shown by the bands at $6.21,11.48,12.24$, and $13.35 \mu$. Substitution on the rings in various ways or fused rings produce the three-band pattern between 11 and $13.5 \mu$. In addition, two bands are found at 13.68 and $13.87 \mu$ that are difficult to in terpret. They are probably due in part to $-\mathrm{CH}_{2}$ chains, as in the water-white oils, because there are certainly aliphatic $\mathrm{CH}_{2}$ and $\mathrm{CH}_{3}$ groups present. Bands comparable in appearance to these were not found in the heavy petroleum fractions previously studied $[2,3]$. These fractions contain oxygen in the form of $\mathrm{O}-\mathrm{H}$ groups absorbing at $2.95 \mu$ (this band could also be due to $\mathrm{N}-\mathrm{H}$ groups), $\mathrm{C}=\mathrm{O}$ groups absorbing at $5.86 \mu$, and perhaps $\mathrm{C}-\mathrm{O}$ groups contributing to the general absorption from 8 to $10 \mu$. Sample I has more $\mathrm{C}=\mathrm{O}, \mathrm{O}-\mathrm{H}, \mathrm{C}-\mathrm{O}$, aromatic, and branched aliphatic groups than samples II or III. Sample III has the least absorption by $\mathrm{C}=\mathrm{O}$ groups, whereas sample II has the least branching and absorption by $\mathrm{O}-\mathrm{H}$ groups. Sample II has a stronger band at $6.21 \mu$ but weaker bands at 12.24 and $13.35 \mu$ than sample III. In none of these are the differences in the aromatic bands very great.

As expacted, the dark-oil fractions separated from the weathered asphalts show increased absorption by $\mathrm{C}=\mathrm{O}$ groups, indicating increases in carbonyl concentrations by factors of about 1.4 for sample II and about 2 for I and III. There are no changes in the $\mathrm{O}-\mathrm{H}$ bands, and only sample I shows increased adsorption in the $\mathrm{C}-\mathrm{O}$ band region. The aromaticity of the samples is not greatly changed, but may be slightly reduced by weathering. In all of the samples the pair of bands at 13.68 and $13.87 \mu$ have been greatly accentuated. As in the case of the waterwhite oils, the dark oils separated from weathered asphalts II and III are nearly identical, although the dark-oil fractions from the unweathered asphalts are different.
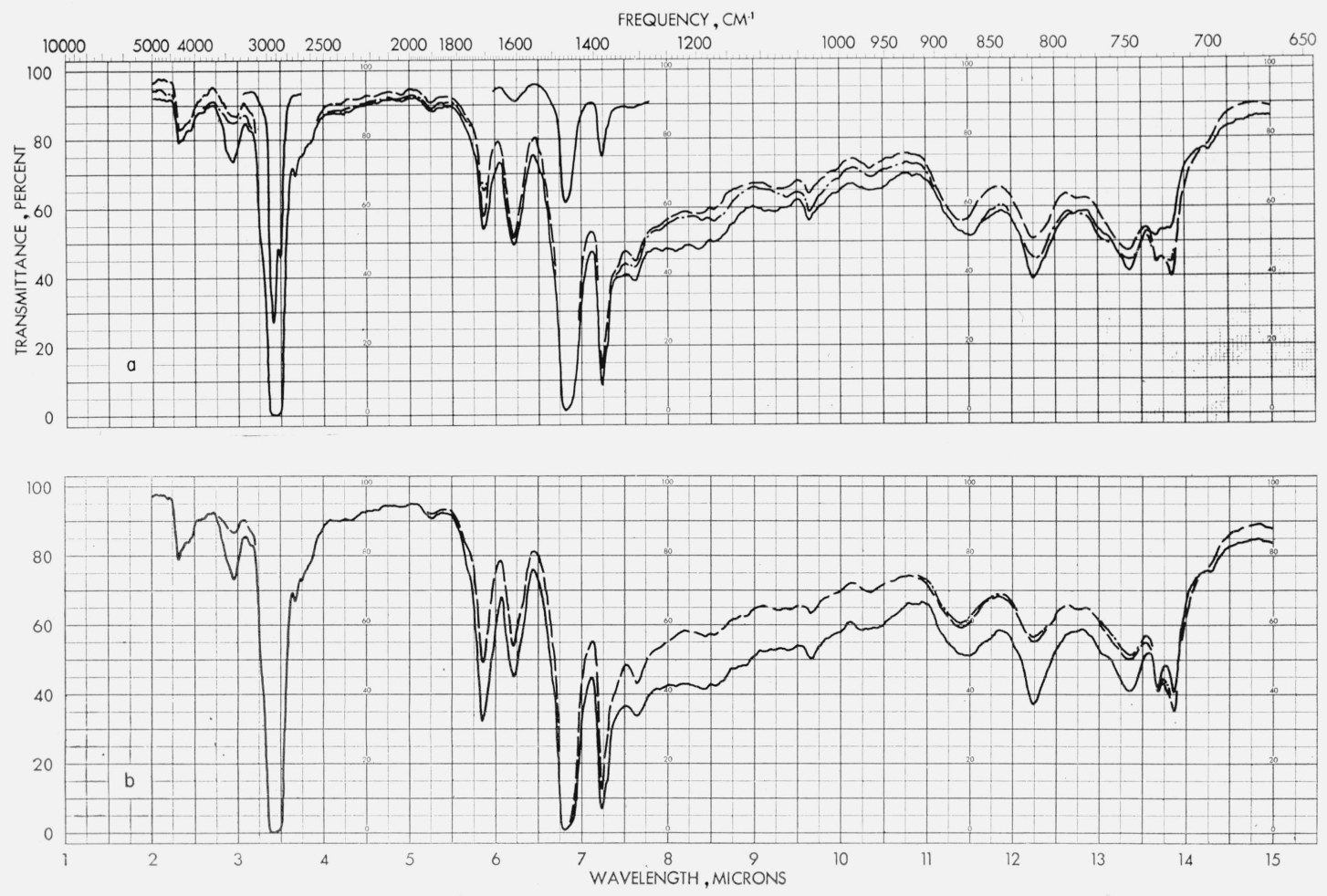

Figure 2. Infrared spectra of dark-oil fractions of asphalts.

a, Unweathered; b, weathered.

I, _ _ ; II, __ _ _ _ III, 



FIGURE 3. Infrared spectra of asphaltic resin fractions of asphalts.

a, Unweathered; b, weathered.

I, __ _ _ II, ; III,

\subsection{Asphaltic Resins}

The asphaltic resin fractions (fig. 3) appear to be more aromatic ${ }^{3}$ than the dark oils, and to contain more $\mathrm{C}=\mathrm{O}$ groups. The broad absorptions near $3 \mu$ extend to longer wavelengths than they do in the dark oil, and there is a definite absorption at $6 \mu$, especially noticeable in sample I, suggesting the presence of amides or amines. The strong band found in all samples at $9.62 \mu$ is puzzling. It occurs in a region where certain $\mathrm{C}-\mathrm{O}, \mathrm{S}=\mathrm{O}$, and $\mathrm{Si}-\mathrm{O}$ groups absorb [5]. Because the intensity of absorption by these groups is fairly large, the band at $9.62 \mu$ does not necessarily indicate a high concentration. The band does not coincide with the band found in this region in the spectrum of fuller's earth [6] $\mu$.

Of the three samples, material I is probably most aromatic, and contains more oxygenated groups than the others. The band at $9.62 \mu$ is strongest in samples I and III.

The fractions obtained from weathered asphalt show increased $\mathrm{C}=\mathrm{O}$ absorption, as well as stronger

3 This observation is based on the intensity of the band at $6.25 \mu$. The $\mathrm{C}-\mathrm{H}$ out-of-plane vibration bands between 11 and $14 \mu$ are weaker than those in the dark-oil fractions, suggesting that the asphaltic resins contain condensed or highly substituted aromatic ring systems. It is to be emphasized, however, that conclusions based on the assumption of invariant intensities of bands are questionable until the invariance of such bands is well established experimentally. absorption in the $\mathrm{C}-\mathrm{O}$ region. The gain in concentration of carbonyl groups measured at $5.86 \mu$, under the assumption of constant absorptivity of carbonyl groups, is again larger for sample I (about 2.8 times) than for samples II and III (about 1.7 and 1.8 times, respectively). The band at $9.6 \mu$ seems to be weaker in the fractions from weathered asphalt, whereas bands at 8.8 and $7.7 \mu$ become stronger. This is consistent with an oxidation of sulfoxides to form sulfones, for example. Once more, the near identity of the samples from weathered asphalts II and III is striking.

\subsection{Asphaltenes}

The spectra of the asphaltenes (fig. 4) have a washed-out appearance, that is, the contrast between background and absorption peaks is relatively low. This is often the case when rather large particles are observed in suspension, even though scatter is controlled by proper choice of suspension medium $[7,8]$. The spectra show evidence of aliphatic and aromatic groups and for $\mathrm{C}=\mathrm{O}$ and $\mathrm{C}-\mathrm{O}$ groups. However, no $\mathrm{O}-\mathrm{H}$ or $\mathrm{N}-\mathrm{H}$ absorption is observed. There is a little difference among the spectra of unweathered asphaltenes and even less among the weathered specimens. Weathering appears to increase somewhat the aromatic and carbonyl content of the material. 


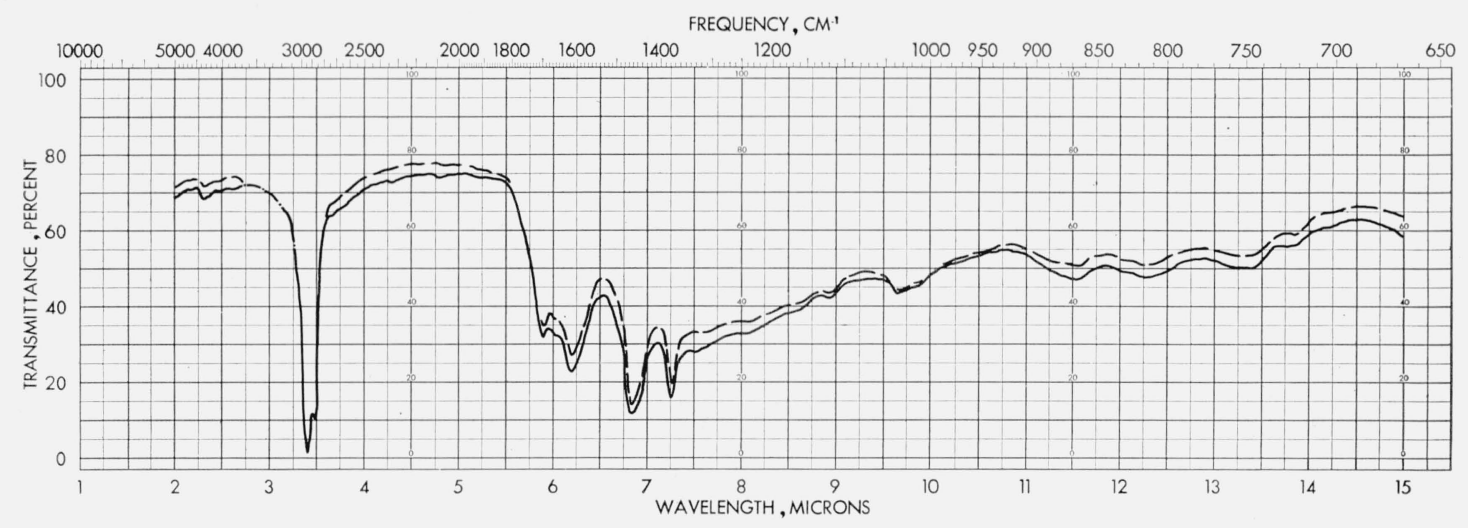

FIGURE 4. Infrared spectra of asphaltenes separated from asphalt $I$.

, Unweathered;

, weathered.

Samples were suspended in potassium iodide pellets, except for observation in the 2.75 - to 3.25 - $\mu$ region, where mineral-oil suspensions were used.

\section{Discussion and Conclusion}

Infrared analysis is most valuable when used in conjunction with other chemical and physical infor mation. The discussion of the structures found in the fractions of asphalts I and II is for the most part in qualitative agreement with the elemental analyses [9] of the same or, in the case of weathered material, similar fractions

All of the fractions of asphalt I have a higher carbon-to-hydrogen ratio than the fractions of II, except for the asphaltenes, and all the fractions of asphalt I contain more oxygen, sulfur, and nitrogen. The carbon-to-hydrogen ratio increases regularly in the order water white oils, dark oils, asphaltic resins, asphaltenes, and, although some oxygen and nitrogen are reported in the dark oils, these elements are more prevalent in the asphaltic resins and asphaltenes. The sulfur analysis, unfortunately, does not necessarily support the possible assignment of the 9.6- $\mu$ band in the asphaltic resins to $\mathrm{S}=\mathrm{O}$ groups.

In general, weathering appears to reduce slightly the carbon-to-hydrogen ratio of all of the fractions and to increase the oxygen content of the dark oils, asphaltic resins, and asphaltenes.

In conclusion, the information derived from the infrared spectra of asphalt fractions can be summarized as follows:

1. The fractions from asphalt III resemble those from asphalt II, both before and after weathering.

2. Water-white oils are predominantly saturated aliphaties, with slight aromatic content. Asphalt II has less aromatic, branched aliphatic, and cycloparaffin content than I. Weathering reduces the aromatic, branched-chain, and cycloparaffin nature, particularly of asphalt I.

3. Dark oils have considerable aromatic structure and some oxygenated groups. Asphalt II has less aromatic, branched chain and oxygenated character than I. Weathering increases the carbonyl content and perhaps reduces the aromatic nature slightly, especially in asphalt I.

4. Asphaltic resins are highly aromatic with carbonyls and other oxygen groups and possibly amide, $\mathrm{S}=\mathrm{O}$, and $\mathrm{Si}-\mathrm{O}$ groups; asphalt I containing more of all of these groups. Weathering increases the $\mathrm{C}=\mathrm{O}$ content and changes the $\mathrm{S}$ or $\mathrm{Si}$ absorption. Again, asphalt $I$ is most affected.

5. Asphaltenes are aromatic with $\mathrm{C}=\mathrm{O}$ and $\mathrm{C}-\mathrm{O}$ groups. Weathering produces some increases in aromatic and carbonyl content. There seems to be little difference among materials from different asphalts.

The author is grateful to L. R. Kleinschmidt who provided the fractionated samples and to S. H. Greenfeld for his unpublished data on physical and chemical properties of the fractions.

\section{References}

[1] L. R. Kleinschmidt, J. Research NBS 54, 163 (1955) RP2577.

[2] F. J. Linnig and J. E. Stewart, J. Research NBS $\mathbf{5 9}$ (1957) R P2771.

[3] A. R. Glasgow, Jr., D. J. Termini, and J. E. Stewart (unpublished report).

[4] S. H. Greenfeld, Effects of mineral additives on the durability of coatings-grade roofing asphalts, NBS Building Materials and Structures Report 147 (1956).

[5] L. J. Bellamy, The infrared spectra of complex molecules, John Wiley \& Sons, New York, N. Y. (1954).

[6] J. M. Hunt, M. P. Wisherd, and L. C. Bonham, Anal. Chem. 22, 1478 (1950)

[7] M. R. Harvey, J. E. Stewart, and B. C. Achhammer, J. Research NBS 56, 225 (1956) RP2670.

[8] J. E. Stewart, J. Research NBS 54, 41 (1955) RP2563.

[9] S. H. Greenfeld, private communication.

Washington, November 30, 1956. 